\title{
General hospital services for those who carry out deliberate self-harm
}

\author{
Tom Hughes, Susan Hampshaw, Edward Renvoize and David Storer
}

The Royal College of Psychiatrists has published
national guidelines for services for those who carry out
deliberate self-harm. This study aimed to discover
whether these recommendations are being followed.
We conducted a semi-structured interview with a
professional from the accident and emergency
service and one from the specialist service at each of
16 hosplitals in the former Yorkshire Regional Health
Authority. The findings are that services are not adhering
to the guidelines. The production of guidelines without
an adequate implementation strategy is ineffective. The
Department of Health should endorse the College
guidelines, and produce an implementation strategy
to secure the involvement of purchasers and providers.

Deliberate self-harm is a common reason for admission to hospital and is associated with significant morbidity and mortality. Annual rates of admission in the UK are around 250-300 out of 100000 of the population (Hawton \& Fagg, 1992). A number of randomised treatment trials of brief, problem-solving strategies for those who have carried out deliberate self-harm have shown significant psychosocial benefits and trends towards a reduction in the rate of repetition of deliberate self-harm. Hawton et al (1987) found an improvement in psychiatric symptom levels, greater improvement in target problems (in women), and a lower repetition rate in the treatment group. Salkovskis et al (1990) showed a reduction in psychiatric morbidity in the treatment group, and a significant reduction in the rate of repetition at six months, though this was not sustained at one year. McLeavey et al (1994) showed a reduction in the rate of repetition at one year. A definitive study large enough to show a sustained, statistically significant reduction in the rate of repetition is awaited. Nevertheless, the quality of the services for those who carry out deliberate self-harm is important.

In 1984, the Department of Health and Social Security (DHSS) produced guidelines for deliberate self-harm services (Department of Health and Social Security, 1984). These related to several service components such as setting up specific self-harm teams, multi-disciplinary working, and adequate training of staff. More recently, the Royal College of Psychiatrists has published a Consensus Statement (Royal College of Psychiatrists, 1994) setting out detailed standards for the whole service. The recommendations relate to the assessment of adult deliberate selfharm patients by non-psychiatric medical staff and by specialist staff (psychiatric or nonmedical self-harm specialists) in both the accident and emergency (A\&E) department and on in-patient wards.

This study was carried out to determine the extent to which services are following the guidelines set out in the Consensus Statement. There has been a previous survey of general hospital services for those who carry out deliberate selfharm (Hawton \& James, 1995), but this was a postal survey. Our own experience in a previous study suggests this method can introduce flaws and ambiguities when used in this area (Report to the Yorkshire Regional Health Authority, further details available from the authors upon request).

\section{The study}

Between June and October 1995 we surveyed each of the 16 main general hospitals in the former Yorkshire Regional Health Authority. A semi-structured questionnaire was used by one of us (T.H.) to interview a professional from the $A \& E$ department at each hospital and a professional from the local specialist service. The questionnaire was developed for this survey (available from the authors upon request).

\section{Findings}

Sixteen A\&E department professionals were interviewed, of whom 15 were consultants and one a clinical assistant. Seventeen professionals from the specialist service were interviewed, of whom 16 were consultant psychiatrists and one was from a social work background. 


\section{Planning and organisation of services}

A Self-Harm Services Planning Group was reported to exist in two services (13\%), but met regularly in only one.

\section{Assessment by non-psychiatric medical staff in $A \& E$}

Clinical procedures and facilities in the $A \& E$ department An assessment of the immediate risk to the health or safety of the patient was made on the arrival of the patient in A\&E in 14 departments $(88 \%)$. This assessment was documented in only three of the eight departments (38\%) where the A\&E records were available for examination. Separate judgements about physical fitness to wait, level of distress and likelihood the patient would wait to be seen were not made.

Assessment facilities in A\&E The suitability of the assessment facilities in $A \& E$ is shown in Table 1.

Suitability of staff to undertake psychosocial assessment $A \& E$ medical staff were required to carry out psychosocial assessments of patients seen after deliberate self-harm, apart from those who leave without waiting to see a specialist, in five departments (31\%). In two of these, staff were given no training in how to do this.

Clinical assessment and management Facilities were available to allow patients extra time to recover their equanimity in $15 \mathrm{~A} \& \mathrm{E}$ departments. Short-stay wards were available in 14 (88\%). $A \& E$ staff had access to a specialist, at least by telephone, and to social services assistance in all departments. Where a patient was neither admitted to hospital nor assessed by a specialist, it was standard practice for an informant to be contacted in only three departments (19\%).

Communication Where a patient was not admitted or seen by a specialist, the general practitioner (GP) was contacted by $A \& E$ staff

Table 1. Clinical procedures and facilities in the A\&E department

\begin{tabular}{lr}
\hline & $n(\%)$ \\
\hline $\begin{array}{l}\text { Departments with rooms designated for } \\
\text { psychosocial assessment of deliberate self- }\end{array}$ & $4(25)$ \\
harm patients & \\
Departments with private room available & $16(100)$ \\
Room affords privacy & $16(100)$ \\
Room close to, or part of, main A\&E area & $13(81)$ \\
Room contains panic button & $5(31)$ \\
Room contains closed circuit TV & $2(13)$ \\
Room contains telephone with outside dialling $12(75)$ \\
\hline
\end{tabular}

within 24 hours in only three services (19\%). A\&E staff made written contact with the GP within three working days in 14 services $(88 \%)$ but no contact was made at all in one service $(6 \%)$.

\section{Specialist staff}

Planning and organisation of specialist services In $10(63 \%)$ of the specialist services a person was identified with responsibility for overseeing the service. A designated self-harm specialist team existed in four services (25\%). These teams all included one or more trained psychiatric nurse, three included one or more social worker and one an occupational therapist. All offered a service to the A\&E department and in-patient wards during normal working hours. One other service did not have a designated selfharm specialist team. but did have a liaison nurse for one session per week. All out of hours and emergency assessments were carried out by trainee psychiatrists. In 12 services (75\%) all routine specialist assessments were also carried out by trainee psychiatrists. The rota for assessment by psychiatrists comprised named consultant teams (rather than named trainee psychiatrists) in only two of these 12 services (17\%).

Standards for referral on in-patient wards Written guidance explaining the system of referral existed in seven services (44\%), and was available to junior medical staff in six (38\%); to medical nursing staff in two (13\%); and to those making assessments in five (31\%).

Assessment facilities on in-patient wards Only two services had designated rooms available for interviewing deliberate self-harm patients on each ward. Fifteen (94\%) had a quiet space available on each ward. Difficulties were encountered finding a suitable place to hold an interview in half of the services.

Suitability of specialist staff to undertake psychosocial assessment In 15 specialist services a person was identified as responsible for training including the assessment of patients following deliberate self-harm. However, in no service did training of specialist staff meet the College guidelines. For trainee staff new to the task assessments were observed until they were judged competent in six services $(38 \%)$. The supervisor made face-to-face contact with the patient in at least five cases in no services. Relevant literature was pointed out to new staff in two services (13\%). Every case was supervised during the first six months in four services (25\%). No written supervision policies were available. In only three (19\%) services did written guidance 
exist on the extent to which the specialist was providing advice to the $A \& E$ and medical teams or acting autonomously in making management decisions. Only three services had written guidance on the lines of responsibility within the specialist service.

Clinical assessment and management Patients could be required to wait more than three hours in A\&E for specialist assessment in only one department. The policy of the specialist service included attendance within one hour at an emergency assessment in $A \& E$, or on an inpatient ward, in only five services (31\%). For nonurgent cases patients were seen on the same working day if the referral was made in the first part of the morning, or within 24 hours if the referral came later in the day, in 13 services (81\%).

Communication When specialist staff saw a patient in $A \& E$, they never contacted the GP routinely, as recommended in the College guidelines, but always did so if they felt it was necessary. Regarding in-patient wards, written guidance on whether clinical responsibility for discharge lay with the medical or specialist team existed in only one service (6\%). Written guidance on which team had clinical responsibility for making further arrangements existed in only two services (13\%), and for communication with the GP in only one (6\%).

Assessment by general medical staff on inpatient wards Written policy regarding assessment by general medical staff existed in two services (13\%). It was stated in the policy of only one of these services that an assessment of the immediate risk of suicide should be made in each case. Some training in making psychosocial assessments was given to these staff in only seven (44\%) services. This training ranged from part of a lecture to part of a lecture plus one hour of consultant teaching.

Availability of information on patients Nine A\&E departments had a computerised case register which could be used to provide information on the numbers of patients attending hospital following deliberate self-harm.

\section{Comment}

The methodology we have used enabled us to overcome some of the problems of validity encountered in our previous study (Report to the Yorkshire Regional Health Authority, details available from the authors upon request) and in that of Hawton \& James (1995). We were able to see documentation where it was reported to exist, and to inspect facilities such as interview rooms.

There was little evidence of active planning of services. Few self-harm services planning groups, recommended in the College guidelines, have been established. However, most services have a computerised patient register, which could be used to provide the basic details on patients necessary for service planning.

Every patient should have a psychosocial assessment by staff specifically trained for this task (Department of Health and Social Security, 1984). Substantial numbers of patients are known to leave the $A \& E$ department without seeing a specialist (Owens, 1990), but A\&E doctors in this survey received little or no training in psychosocial assessment. The lack of subsequent communication with an informant and the GP in such circumstances gives further cause for concern. Even if all cases are subsequently referred to specialists, general medical staff should make an assessment of the risk of suicide in each case (Royal College of Psychiatrists, 1994), but lack the training to do so. Training for specialists also fell some way short of the College guidelines. In addition, assessments by the specialist service are most often carried out by trainee psychiatrists on a rota basis. These rotas usually comprised names of trainee psychiatrists rather than named consultant teams, which may reflect a lack of importance placed on this task.

More encouragingly, some dedicated self-harm teams have been established. Assessment rooms were available in most hospitals, though facilities are inadequate in some respects. The lack of essential safety features in the interview rooms of many $A \& E$ departments is a particular cause for concern. In most services routine cases were seen by specialists within the time recommended in the College guidelines, but the specialist would not necessarily attend within the hour in an emergency. This may put patients at risk and does not enhance the reputation of the specialist service.

Why have the College guidelines not been implemented? In our view the reasons include the low priority given to deliberate self-harm by purchasers and providers. The production of national guidelines must be accompanied by an implementation strategy. This should include: guidance on the development of local guidelines to encourage local 'ownership', and guidance on audit of the service. Considerable improvements could be made without additional resources, by better coordination of existing services. For example, where written policies are absent, they can be agreed and documented. However, some services will require new resources. Adequate services must therefore be specified in the contract between the purchaser and the provider. and there should be proper evaluation of these 
services to ensure that these standards are being met.

\section{Conclusion}

Current national guidelines produced by the Royal College of Psychiatrists for services for those who carry out deliberate self-harm are not being followed at a local level. The Department of Health should endorse the guidelines and should produce an implementation strategy. This strategy should include a means of securing the involvement of the purchasers and providers.

\section{References}

Department of Health and Social Securty (1984) The Management of Deliberate Self-harm (Health Notice HN (84)25). Heywood: Department of Health and Social Security.

HAWTON, K. \& FAGG, J. (1992) Trends in deliberate selfpoisoning and self-injury in Oxford, 1976-1990. British Medical Journal, 304, 1409-1411.

- \& JAMEs, R. (1995) General hospital services for attempted suicide patients: a survey in one region. Health Trends, 27, 18-21.

-, MCKEOWN, S., DAY, A., et al (1987) Evaluation of outpatient counselling compared with general practitioner care following overdoses. Psychological Medicine, 17. 751-761.
MCLeaVy, B. C., DALY, R. J., LUDGATE, J. W., et al (1994) Interpersonal problem-solving skills training in the treatment of self-poisoning patients. Suicide and LifeThreatening Behaviour, 24, 382-394.

OWENS, D. (1990) Self-harm patients not admitted to hospital. Journal of the Royal College of Physicians of London, 24, 281-283.

ROYAL COLLEge OF PSYChIATRISTS (1994) The General Hospital Management of Adult Deliberate Self-Harm. A Consensus Statement on Standards for Service Provision (Council Report CR32). London: Royal College of Psychiatrists.

SAlkovskis, P., ATHA, C. \& STORER, D. (1990) Cognitivebehavioural problem solving in the treatment of patients who repeatedly attempt suicide: a controlled trial. British Journal of Psychiatry, 157, 871-876.

Tom Hughes, Lecturer in Psychiatry, Level 5. Clinical Sciences Building. St James's University Hospital, Leeds LS9 7TF; Susan Hampshaw, Senior Clinical Audit Officer, Department of Clinical Audit, Edward Renvoize, Consultant in Clinical Audit, Department of Clinical Audit, and David Storer, Consultant Psychiatrist, Department of Liaison Psychiatry, Leeds General Infirmary, Great George Street, Leeds LS1 3EX

*Correspondence 